\title{
Entre a escola e o quartel: a negação do direito à educação
}

\section{Between school and military quarters: the denial of the right to education Entre la escuela y el cuartel: la negación del derecho a la educación}

\section{ANDRÉIA MELLO LACÉ CATARINA DE ALMEIDA SANTOS DANIELLE XABREGAS PAMPLONA NOGUEIRA}

\begin{abstract}
Resumo: Este artigo analisa a militarização nas escolas públicas com o objetivo de extrair evidências sobre a efetivação da garantia do direito à educação com qualidade nesse modelo de gestão. Analisa os pressupostos da militarização à luz dos preceitos constitucionais do direito à educação e da qualidade socialmente referenciada. Foram realizadas análises documentais em fontes primárias e secundárias, matérias jornalísticas e produções teóricas sobre o tema. Concluiuse que o modelo analisado preconiza a negação do direito à educação e da efetivação do princípio da qualidade socialmente referenciada.
\end{abstract}

Palavras-chave: Militarização; escola pública; direito à educação; qualidade.

Abstract: The text analyzes the militarization in public schools with the objective of extracting evidence about the guarantee of the right to quality of education in this model. It analyzes the assumptions of the militarization in the light of the constitutional precepts of the right to education and socially referenced quality. Documentary analyses were performed in primary and secondary sources, journalistic articles and theoretical productions on the subject. It was concluded that the analyzed model advocates the denial of the right to education and the implementation of the socially referenced quality principle.

Keywords: Militarization; public school; right to education; quality.

Resumen: Este artículo analiza la militarización en las escuelas públicas con el objetivo de extraer evidencia sobre la garantía del derecho a la educación de calidad en este modelo de gestión. Analiza los supuestos de la militarización a la luz de los preceptos constitucionales del derecho a la educación y de la calidad socialmente referenciada. Fueron realizados análisis documentales en fuentes primarias y secundarias, artículos periodísticos y producciones teóricas sobre el tema. Se concluyó que el modelo analizado preconizar la negación del derecho a la educación y la implementación del principio de calidad socialmente referenciado.

Palabras clave: militarización; escuela pública; derecho a la educación; calidad 


\section{INTRODUÇÃO}

O direito à educação é assegurado pela Constituição Federal de 1988, tendo como um dos princípios o da garantia do padrão de qualidade. Para atender ao dispositivo, os sistemas de ensino passaram a propor estratégias para a universalização da educação básica e a melhoria da qualidade educacional, a partir da década de 1990. Dentre as estratégias de melhoria da qualidade, desde 1999, o Estado de Goiás implementou o sistema de militarização de escolas públicas e hoje conta com o maior número de escolas militarizadas no Brasil. Outros Estados, como Bahia, Amazonas, Rondônia, e o Distrito Federal também admitiram o modelo como possibilidade resolutiva da "má qualidade das escolas públicas" e o implementaram com características e estratégias próprias.

No âmbito federal, em julho de 2019, o Ministério da Educação (MEC), em parceria com a União Nacional dos Dirigentes Municipais (Undime) e com o Conselho Nacional de Secretários de Educação (Consed), lançou documento, em apresentação de PowerPoint, intitulado "Compromisso Nacional pela Educação Básica”. A visão de futuro do referido documento é, até 2030, tornar o Brasil referência em educação básica na América Latina, pois acredita-se e propaga-se que "O insucesso escolar na educação básica é um problema concentrado na rede pública de ensino” (BRASIL, 2019).

O documento apresenta diagnóstico e ações breves que contemplam desde a educação infantil, o ensino fundamental, médio, à educação de jovens e adultos (EJA), formação docente e gestão educacional. Além disso, apresenta um conjunto de dez ações intituladas "Projetos Transversais". Dentre essas ações está a implantação de escolas cívico-militares (ECM), única ação com breve explicação desdobrada em duas telas, em que se vislumbra a intenção do governo em fomentar e fortalecer as escolas cívico-militares. O referido documento não explicita como será esse fomento e esse fortalecimento, mas acena que uma das metas é igualar o Índice de Desenvolvimento da Educação Básica (Ideb) das escolas públicas do ensino básico ao Ideb dos colégios militares, conforme gráfico a seguir: 


\section{Gráfico 1: Média nacional do Ideb nos Ensinos Fundamental e Médio}

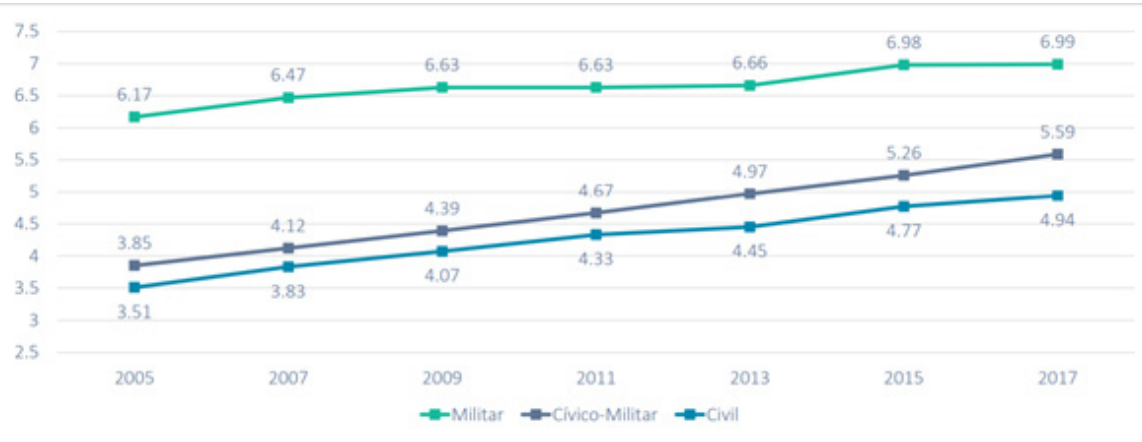

Fonte: BRASIL, 2019, p. 29.

O critério de qualidade escolhido para a adoção do modelo proposto nas escolas se refere ao Ideb, cujo cálculo se dá a partir de dados de fluxo escolar (aprovação) e resultados de desempenho nas avaliações externas, Prova Brasil e Avaliação Nacional da Educação Básica (Aneb) - ambos instrumentos pertencentes ao Sistema Nacional de Educação Básica (Saeb). A partir da interpretação da diferença de desempenho das esferas administrativas, o governo federal atesta a falência do modelo de gestão da educação básica pública, atribuindo a este uma das causas para o insucesso escolar.

Parece-nos claro que a opção do executivo para a resolução no insucesso escolar também é a de implementação do modelo de gestão militarizada das escolas públicas como garantia de qualidade do processo educacional. O modelo pressupõe parcerias entre a Secretaria de Segurança Pública e a Secretaria de Educação. Geralmente, a Secretaria de Segurança Pública assume a gestão administrativa/disciplinar, ao passo que a Secretaria de Educação desenvolve a gestão pedagógica das escolas.

Pautada, então, no argumento de que a qualidade educacional não é alcançada pela rede pública de educação básica, a militarização dessas escolas tem ocupado cada vez mais espaço na agenda de muitos governos estaduais e do governo federal. Desse modo, o presente artigo objetiva extrair evidências sobre a efetivação da garantia do direito à educação com qualidade, conforme princípios da Constituição de 1988, na proposta do modelo de militarização de escolas públicas. Para isso, parte da compreensão da educação como luta de classe e direito social. Em seguida, analisa os pressupostos do modelo de militarização à luz dos preceitos constitucionais do direito à educação e da perspectiva da qualidade socialmente referenciada, por meio de análises documentais em 
fontes primárias e secundárias, incluindo análise de matérias jornalísticas, além de produções teóricas sobre os temas envolvidos. Por fim, apresenta algumas questões sobre a efetivação do modelo discutido.

\section{A EDUCAÇÃO COMO LUTA DE CLASSE E DIREITO SOCIAL}

Marx e Engels (1999) iniciam o Manifesto do Partido Comunista afirmando que a história de toda a sociedade é a história da luta de classes, da luta entre opressores e oprimidos, que sempre estiveram em constante oposição uns aos outros, travando "uma luta ininterrupta, ora oculta ora aberta". Assim, não é possível pensar o direito à educação sem considerar a lógica de que a concepção de educação e quem a ela deve ter direito está intrinsecamente ligada às lutas travadas entre as diferentes classes sociais e nos diferentes momentos históricos.

Aníbal Ponce (2001), ao analisar as diferentes perspectivas de educação nos diferentes períodos da história da humanidade, aponta que nas comunidades primitivas a coletividade era pequena,

assentada sobre a propriedade comum da terra e unida por laços de sangue, os seus membros eram indivíduos livres, com direitos iguais, que ajustaram as suas vidas as resoluções de conselho formado democraticamente por todos os adultos, homens e mulheres, da tribo. O que era produzido em comum era repartido com todos, e imediatamente consumido. O pequeno desenvolvimento dos instrumentos de trabalho impedia que se produzisse mais do que o necessário para a vida cotidiana e, portanto, a acumulação de bens (PONCE, 2001, p. 17).

Nessas comunidades, segundo o autor, mulheres e homens estavam em pé de igualdade e o mesmo acontecia com as crianças, que até os sete anos acompanhavam os adultos em todos os seus trabalhos. Assim, não existia um único responsável pelo processo educativo das crianças, fazendo com que o aprendizado se desse por meio da convivência diária que mantinha com os adultos. Isso fazia com que elas aprendessem as crenças e as práticas do seu grupo social.

Um pouco mais tarde, quando a ocasião o exigia, os adultos explicavam as crianças como elas deveriam comportar-se em determinadas circunstâncias. Usando uma terminologia a gosto dos educadores atuais, diríamos que, nas comunidades primitivas, o ensino era para a vida e por meio da vida; para aprender a manejar os arcos a criança caçava; para aprender a guiar um barco, navegava. As crianças se educavam tomando parte nas funções da coletividade. E, porque tomavam parte nas funções sociais, elas se mantinham, não obstante as diferenças naturais, no mesmo nível que os adultos (PONCE, 2001, p. 19, grifos do autor). 
Nessa perspectiva, Ponce (2001, p. 19) ainda aponta que "a educação na comunidade primitiva era uma função espontânea da sociedade em conjunto, da mesma forma que a linguagem e a moral".

Para o autor, essa concepção de educação, como uma função espontânea da sociedade, por meio da qual as novas gerações se assemelham às mais velhas, foi se transformando e passou a não ter mais serventia à medida que a sociedade foi se transformando numa sociedade dividida em classes.

A forma dos membros da comunidade se organizarem na sociedade primitiva pautava-se na colaboração entre os homens, fundamentava-se na propriedade coletiva e nos laços de sangue. Mas, a partir do momento em que a sociedade começou a se dividir em classes, o autor aponta que a propriedade passou a ser privada e os vínculos, que até então eram de sangue, deram lugar a um novo vínculo inaugurado pela escravidão, qual seja, a imposição do poder do homem sobre o homem. A partir desse momento, Ponce (2001, p. 26, grifos do autor) afirma que

os fins da educação deixaram de estar implícitos na estrutura total da comunidade. Em outras palavras: com o desaparecimento dos interesses comuns a todos os membros iguais de um grupo e a sua substituição por interesses distintos, pouco a pouco antagônicos, o processo educativo, que até então era único, sofreu uma partição: a desigualdade econômica entre os "organiz̧adores"-cada vez mais exploradores - e os "executores" - cada vez mais explorados - trouxe, necessariamente, a desigualdade das educações respectivas. As famílias dirigentes que organizavam a produção social e retinham em suas mãos a distribuição e a defesa organizaram e distribuíram também, de acordo com os seus interesses, não apenas os produtos, mas também os rituais, as crenças e as técnicas que os membros da tribo deviam receber.

Para o referido autor, na comunidade primitiva, quando não havia divisão de classes, quando a vida social diferia pouco de indivíduo para indivíduo, as práticas dos grupos faziam com que as crianças seguissem o caminho do hábito, não sendo necessária, portanto, nenhuma disciplina. As relações de dominação e submissão que surgiram nas tribos com a divisão de classes demarcam as diferenças entre os indivíduos, definindo-os de acordo com o lugar que cada um ocupava na produção. Ainda de acordo com Ponce (2001), isso trouxe como resultado o fato de que a educação das crianças já não pode mais se dar de forma espontânea no seu meio ambiente. É preciso organizar a educação sistemática, organizada e violenta, pautada em outra concepção, que reflita a mesma noção de hierarquia que apareceu na estrutura econômica da tribo. Nessa nova organização, é naturalizada a existência de deuses dominadores e crentes submissos. Essas crenças estão tão ligadas à essência das classes sociais que até a vida após a morte, presente na fé de todos, torna-se um privilégio dos nobres. 
Não é necessária dizer que a educação imposta pelos nobres se encarrega de difundir e reforçar esse privilégio. Uma vez constituídas as classes sociais, passa a ser um dogma pedagógico a sua conservação, e quanto mais a educação conserva o status quo, mais ela é julgada adequada. Já nem tudo o que a educação inculca nos educandos tem por finalidade o bem comum, a não ser na medida em que "esse bem comum" pode ser uma premissa necessária para manter e reforçar as classes dominantes. Para estas, a riqueza e o saber; para as outras, o trabalho e a ignorância (PONCE, 2001, p. 28, grifos do autor).

Em sua análise, Ponce (2001, p. 36) aponta que toda educação imposta pelas classes proprietárias deve " $1^{\circ}$ destruir os vestígios de qualquer tradição inimiga, $2^{\circ}$ consolidar e ampliar sua própria situação de classe dominante, e $3^{\circ}$ prevenir uma possível rebelião das classes dominadas". Diz o autor que no campo da educação a atuação da classe dominante se dá nestas três frentes distintas e, embora cada uma dessas frentes possa exigir "uma atenção desigual segundo as épocas, a classe dominante não as esquece nunca" (2001, p. 36).

Para ele, no momento em que ocorre a transformação da sociedade comunista primitiva em sociedade dividida em classes, os fins da educação voltam-se especificamente para a destruição das tradições do comunismo tribal, a construção do ideário de que o objetivo das ações das classes dominantes é assegurar a vida das dominadas, além de coibir, extirpar e corrigir qualquer movimento de protesto da parte dos oprimidos. Assim,

O ideal pedagógico já não pode ser o mesmo para todos; não só as classes dominantes têm ideais muito distintos dos da classe dominada, como ainda tentam fazer com que a massa laboriosa aceite essa desigualdade de educação como uma desigualdade imposta pela natureza das coisas, uma desigualdade, portanto, contra a qual seria loucura rebelar-se (PONCE, 2001, p. 36).

Marx e Engels (1999) apontam para as diferentes posições sociais que se fizeram presentes em praticamente todos as épocas da história, sendo possível encontrar por quase toda parte a múltipla gradação das posições sociais e que a "moderna sociedade burguesa, saída do declínio da sociedade feudal, não aboliu as oposições de classes. Apenas pôs novas classes, novas condições de opressão, novas configurações de luta, no lugar das antigas" [mas, segundo os autores, na época da burguesia], a sociedade toda cinde-se, cada vez mais, em dois grandes campos inimigos, em duas grandes classes que diretamente se enfrentam: burguesia e proletariado (MARX; ENGELS, 1999, p. 67).

É no âmbito dessa sociedade cindida, dividida em classes cada vez mais antagônicas, que urge a disputa para que os direitos saiam da esfera do divino, deixem de ser privilégios de alguns e passem a se constituir em direitos sociais. 
Mas é também no âmbito dessa sociedade que a disputa pela manutenção dos privilégios e a negação dos direitos para os que não fazem parte das castas ou dos grupos detentores do poder se dão.

A luta para que a educação, assim como os demais direitos, se constitua em direito social e não em privilégio é uma luta entre classes. Se por um lado, a classe trabalhadora busca a superação das estruturas de poder que a mantém na condição de oprimida e destituída de direito, por outro, os detentores dos meios de produção usam de todos os aparatos que dispõem para manter seus privilégios e garantir, assim, sua condição de opressores. Nesse sentido, a luta por uma educação que garanta processos formativos que desnaturalize a estrutura social vigente, que é na sua essência pautada em desigualdades das mais diversas ordens, está permeada de conflitos, tendo em vista que o que está em disputa são concepções de educação, de homem, de mundo e de sociedade. Trata-se de uma batalha entre classes antagônicas que, em que pese as contradições no seu interior, uma busca a superação e a outra a manutenção das estruturas de poder.

A positivação do direito à educação no Brasil, bem como a luta pela sua concretização no campo das relações sociais concretas, mobilizou educadores ao longo do tempo. Anísio Teixeira, Dermeval Saviani, Darcy Ribeiro e Florestan Fernandes são alguns desses exemplos. A incansável luta de Anísio Teixeira pela educação pública, gratuita, laica e de qualidade é conhecida de todos nós. Em fins da década de 1950, nos debates travados em torno da aprovação da primeira Lei de Diretrizes Bases no Brasil, o protagonismo de Anísio foi essencial para situar a importância da educação pública para todos, inclusive como principal elemento, senão o mais estruturante, para se fundar a república brasileira e consolidar os valores supremos de uma sociedade fraterna, pluralista e sem preconceitos.

Todavia, o movimento pendular da história brasileira e o esgarçamento das classes sociais conduziram o país para 21 anos de Ditadura Civil-Militar. O direito à educação durante esse período foi estudado por Góes e Cunha (1988) e Cunha (2016). Esses autores, entre outros elementos, destacam o recuo na laicidade do Estado, com forte influência das igrejas católicas, inclusive, na determinação dos conteúdos da disciplina Moral e Cívica e na forte presença de religiosos na condução das políticas educacionais. Além disso, o preceito da sagrada família (Jesus, Maria e José) se apresenta como modelo ideal, ao passo que todas as outras reconfigurações familiares eram tidas como anormais (CUNHA, 2016). Em nome da segurança nacional, da ordem e do patriotismo, o dissenso foi coibido.

O recuo na laicidade do Estado foi proporcional ao recuo na qualidade da educação oferecida. Penin e Vieira (2002) e Carvalho (2016) evidenciam a massificação da educação a partir da Lei 5.692 de 1971, que, se por um lado, 
ampliou de 4 para 8 anos a obrigatoriedade do Estado na garantia da educação pública, por outro descontinuou o financiamento da educação, acarretando elevado número de reprovação e evasão, alto índice de analfabetismo, desprestígio e desvalorização docente, distorção série/idade e precarização dos serviços educacionais oferecidos.

A IV Conferência Brasileira de Educação (CBE), realizada em Goiânia nos dias 2 e 5 de setembro de 1986, foi um importante marco para o manifesto dos educadores na assunção de suas responsabilidades na (re) construção da democracia e para a superação dos impeditivos para a universalização da educação pública e de qualidade para todos. As reivindicações dos educadores foram inscritas na Carta de Goiânia e seu conteúdo influenciou a Constituição Federal de 1988, na seção referente à educação (ANDE; ANPED; CEDES, 1986).

A Constituição cidadã, em seu artigo 205, define que a educação é direito de todos e dever do Estado, da família mediada pela sociedade e visa três finalidades: o pleno desenvolvimento da pessoa, seu preparo para o exercício da cidadania e sua qualificação para o trabalho. Estabelece ainda, no artigo 206, oito princípios pelos quais o ensino deve ser ministrado. Entre eles: a igualdade de condições para o acesso e permanência na escola, a liberdade de aprender, ensinar, pesquisar e divulgar o pensamento, a arte e o saber, o pluralismo de ideias e concepções pedagógicas (BRASIL, 1988).

O tempo presente reverbera, portanto, dilemas educacionais que pareciam ter encontrado certa segurança jurídica a partir do pacto social de 1988, especialmente aqueles dilemas referentes ao direito à educação. De 1988 até 2014, um conjunto de emendas constitucionais, leis ordinárias, complementares, decretos e diretrizes especificaram e prescreveram aspectos relativos ao direito à educação consignados na Constituição Cidadã. Entre elas destacam-se: a Lei de Diretrizes e Bases da Educação Nacional de 1996, as leis que instituíram a política de fundos para financiar inicialmente o ensino fundamental e a partir de 2007 toda a educação básica, os Planos Nacionais de Educação e a Emenda Constitucional 59 de 2009 - que assegurou o dever do estado à educação básica obrigatória e gratuita dos 4 aos 17 anos, dentre outras.

\section{O MODELO DE MILITARIZAÇÃO DE ESCOLAS PÚBLICAS: O DIREITO À EDUCAÇÃO COM QUALIDADE EM PAUTA}

Conforme sinalizado anteriormente, o modelo de militarização é motivado, sobretudo, pela necessidade de melhoria da qualidade educacional. Nesse sentido, o Ministério Público do Distrito Federal expediu Nota Técnica a fim de conferir publicidade ao posicionamento favorável das Promotoras 
de Justiça de Defesa da Educação sobre a implementação da escola de gestão compartilhada no DF. A Nota afirma que não vai julgar qualquer abordagem de conteúdo do mérito da proposta de militarização, mas restringir-se aos aspectos jurídicos e formais, privando-se assim de emitir juízo de valor de escolhas políticas do Poder Executivo (MPDFT, 2019). Por outro lado, ao contextualizar a questão, a Nota justifica o aumento da demanda, por parte da sociedade civil, por matrículas em escolas militares devido à qualidade do ensino constatada no Ideb e afirma textualmente que "não se pode ignorar que o modelo de educação adotado no Brasil tem apresentado resultados insatisfatórios nos níveis de aprendizagem, em especial entre os estudantes carentes" (MPDFT, 2019, p. 7).

Em Rondônia, o Ministério Público impetrou Ação Direta de Inconstitucionalidade (ADIN), em face da Constituição Estadual, contra a militarização das escolas públicas. No voto de alguns desembargadores, é possível verificar, mais uma vez, a justificativa do voto favorável à militarização, já que as "escolas militares" são exemplos de qualidade, hierarquia e disciplina (TJ/RO, 2019).

Analisou-se ainda postagens que foram feitas no perfil do Sindicato dos Professores do Distrito Federal (SINPRO-DF), na plataforma Facebook, em agosto de 2019. Dentre diversos tipos argumentativos, sobressaem aqueles que alegam a qualidade do colégio militar do DF e o desejo da maioria dos pais de oferecerem esse ensino para os seus filhos.

Observou-se, a partir disso, uma forte tendência nas diferentes esferas da sociedade em compreender os colégios militares e as escolas militarizadas como sinônimos e logo providos da mesma organização, gestão e financiamento. Sobre essa questão, cabe esclarecer que o Brasil dispõe de 13 escolas militares que compõem o Sistema Colégio Militar do Brasil. Essas escolas são geridas e mantidas pelo Exército Brasileiro. A organização do ensino militar é regida por lei específica, conforme assegura o artigo 83 da Lei de Diretrizes e Bases da Educação de 1996. No conjunto do ordenamento legal, a Lei 9.786 de 1999, que dispõe sobre o ensino no Exército Brasileiro, foi regulamentada pelo Decreto 3.182 de 1999, cujo teor sofreu alteração em 2017, por meio do Decreto 9.171, de 17 de outubro de 2017. Em outras palavras, as escolas militares previstas em lei, cujo aluno custa em média $\mathrm{R} \$ 19$ mil reais, três vezes mais que um aluno da escola pública regular (BOLSONARO..., 2019), não podem ser tomadas como sinônimo de escolas militarizadas.

Em outra direção, as escolas militarizadas não integram o Sistema Colégio Militar do Brasil. Elas continuam fazendo parte do sistema estadual e/ou municipal de ensino e são transformadas, geralmente, por meio de parcerias entre 
a Secretaria de Segurança Pública e a Secretaria de Educação, em escolas geridas pela polícia militar. Aos policiais militares da reserva cabe a gestão administrativa e disciplinar e aos professores a gestão pedagógica.

Desse modo, institui-se um modelo de gestão nas escolas das redes públicas do ensino que incorpora rotinas e procedimentos disciplinares do padrão militar. Parafraseando Rui Barbosa (1893), a polícia gerindo a escola leva ao militarismo e subsume as finalidades precípuas da educação aos ditames da hierarquia, da obediência e da subordinação.

Apesar de não existir um único modelo de militarização implementado pelos sistemas de ensino no Brasil, os princípios fundantes convergem para a adoção de uma perspectiva de qualidade baseada na padronização e na dissociação dos aspectos administrativos e pedagógicos da gestão escolar. Essas constatações implicam na retomada do princípio constitucional da qualidade na educação disposto no Art. 206. Esse disposto atribui à educação brasileira a garantia do padrão de qualidade, ao mesmo tempo que estabelece a gestão democrática do ensino público.

O entendimento acerca da qualidade na educação converge, numa perspectiva democrática, para o conceito de qualidade social da educação ou o de qualidade socialmente referenciada.

Segundo Belloni (2003, p. 232),

Educação de qualidade social é aquela comprometida com a formação do estudante com vistas à emancipação humana e social; tem por objetivo a formação de cidadãos capazes de construir uma sociedade fundada nos princípios da justiça social, da igualdade e da democracia.

Nesse sentido, reforça-se o pressuposto de que, de acordo com Dourado e Oliveira (2009), a discussão acerca da qualidade da educação remete à definição do que se entende por educação. Assim, promove-se

o reconhecimento de que a qualidade da escola para todos, entendida como qualidade social, implica garantir a promoção e atualização histórico-cultural, em termos de formação sólida, crítica, ética e solidária, articulada com políticas públicas de inclusão e de resgate social (DOURADO; OLIVEIRA, 2009, p. 211).

Logo, entende-se que a qualidade social é aquela que assegura o exercício da cidadania, visando à construção de uma sociedade mais justa e igualitária. Sobre essa perspectiva de qualidade, Flach (2005) define como indicadores: educação como direito de cidadania; participação popular na gestão; valorização dos 
trabalhadores em educação; e recursos adequados. A fim de centrar as discussões no objeto deste artigo - a militarização -, tomou-se como referência apenas os dois primeiros.

O indicador de educação como direito de cidadania pressupõe que educação deve basear-se numa perspectiva de emancipação humana e social e permite que os indivíduos se tornem verdadeiros sujeitos de sua própria história. Além disso, demanda uma política de inclusão social para propiciar à população mecanismos que viabilizem sua entrada num contexto social mais amplo.

O indicador de participação popular na gestão é compreendido como um verdadeiro exercício democrático.

\begin{abstract}
Participar consiste em colaborar de forma efetiva na construção de um plano de ação coletivo, observando que essa construção deve superar o conflito das partes e alcançar um consenso, mas não o consenso entendido como aceitação da concepção defendida pela classe dominante, o qual impossibilita totalmente a elaboração de um projeto contra-hegemônico, mas o consenso baseado no diálogo, onde a vOz mais fraca, mesmo que oriunda de uma ínfima minoria, é ouvida e considerada (FLACH, 2005, p. 12).
\end{abstract}

Tomando como base os entendimentos apresentados, compreende-se que o processo de militarização das escolas públicas visa promover uma perspectiva de qualidade muito distanciada da noção de qualidade socialmente referenciada. Alguns argumentos podem ser levantados, a fim de subsidiar essa conclusão.

O primeiro deles se refere ao fator exercício da cidadania e da liberdade individual. Nesse aspecto, a padronização exigida pelo processo de militarização fere os preceitos da liberdade individual e do respeito à diversidade. Compreendese que o sujeito que compõe a escola pública é diverso, possui as suas diferenças e deve ser respeitado em sua própria diversidade. A qualidade social, portanto, não se baseia na eliminação da diferença como pressuposto de melhoria.

Assim, a militarização fere a garantia da liberdade individual ao instituir a padronização de vestimentas, comportamentos, formas de expressão, manifestações culturais, interfere diretamente na constituição da identidade social desses sujeitos, os quais devem ter assegurados o seu pleno desenvolvimento e o exercício da cidadania.

O segundo, dentre outros, diz respeito ao pressuposto de que não há qualidade social sem uma gestão democrática. A perspectiva de separar as dimensões administrativas e pedagógicas na gestão escolar reforça o caráter tecnicista, prescritivo e normativo, admitindo-se que a atividade-fim da escola (pedagógica) pode ser dissociada do seu processo de gestão. 
Essa separação desconsidera a diversidade das instituições escolares e a sua autonomia para a elaboração de suas propostas pedagógicas. Dessa forma, também leva ao apagamento da identidade da própria escola ao desconsiderar a diversidade da dimensão socioeconômica e a heterogeneidade e pluralidade cultural.

Além disso, diminui a função do gestor escolar, o qual atua nas dimensões pedagógica, administrativa e política, ao inserir um agente de autoridade, com visão educacional limitada e cuja atividade-fim não coincide com a função escolar.

Geralmente, a organização e o funcionamento das polícias, sobretudo da polícia militar, são baseados na obediência ao comando, na hierarquia rígida e na disciplina. Como apontam os regimentos dessas PMs, a hierarquia e a disciplina são a base institucional da Polícia Militar, assim como a autoridade e a responsabilidade que crescem com o grau hierárquico.

Não por acaso, apontam que o respeito à hierarquia deve ser observado e mantido em todas as circunstâncias da vida, entre os policiais militares. O Art. 13 do regimento da Polícia Militar do Distrito Federal, por exemplo, traz ideais que são comuns no regimento de todas as polícias militares do país, quais sejam, os conceitos de hierarquia e disciplina que regem o funcionamento da instituição.

\footnotetext{
$\int 1^{\circ}$ - A hierarquia é a ordenação da autoridade, em níveis diferentes, dentro da estrutura da Polícia Militar, por postos e graduações. Dentro de um mesmo posto ou graduação, a ordenação faz-se pela antiguidade nestes, sendo o respeito à hierarquia consubstanciado no espírito de acatamento da autoridade.

$\S 2^{\circ}$ - Disciplina é a rigorosa observância e acatamento integral da legislação que fundamenta o organismo policial-militar e coordena seu funcionamento regular e harmônico, traduzindo-se pelo, perfeito cumprimento do dever por parte de todos e de cada um dos componentes desse organismo.
}

$\mathrm{Na}$ lógica da hierarquia e disciplina, a subordinação é elemento fundante na constituição da instituição militar, assim como no funcionamento das unidades de comando. A subordinação militar por definição constitui-se no respeito ao princípio da hierarquia, no acatamento das ordens dos superiores, que devem ser plena e prontamente executadas, sob pena de ser acusado de transgressor e exemplarmente punido. Entre as consideradas transgressões por parte do policial militar estão o retardamento da execução de qualquer ordem, sem justificativa, e o não cumprimento de uma ordem legal recebida.

É possível observar que os princípios fundamentais que regem a Corporação da Polícia Militar no país são a hierarquia, a disciplina, a obediência e a subordinação. As finalidades precípuas da Polícia Militar nas diferentes unidades federadas são a manutenção da ordem pública e segurança interna dos estados, além de serem, por lei, força auxiliar reserva do Exército. 
Por outro lado, a educação, como inscrita na Constituição, tem como objetivo a formação dos sujeitos nas suas múltiplas dimensões, devendo para isso ser amparada em princípios basilares da democracia e da horizontalidade.

O processo de militarização, ou melhor, de PMzação das escolas em curso no Brasil requer, ainda, refletir sobre os papéis das duas categorias profissionais responsáveis pela efetivação dos direitos estabelecidos no art. $6^{\circ}$ da Constituição Federal de 1988, a saber: educação e segurança.

O parágrafo único do art. 61 da Lei de Diretrizes e Bases da Educação (Lei n. 9.394/96) define que

Art. 61 a formação dos profissionais da educação, de modo a atender às especificidades do exercício de suas atividades, bem como aos objetivos das diferentes etapas e modalidades da educação básica, terá como fundamentos I - a presença de sólida formação básica, que propicie o conhecimento dos fundamentos científicos e sociais de suas competências de trabalho;

II - a associação entre teorias e práticas, mediante estágios supervisionados e capacitação em serviço (BRASIL, 1996).

Já o art. 62 define que formação de docentes para atuar na educação básica far-se-á em nível superior, em curso de licenciatura plena e no desempenho das suas funções. Participar de processos coletivos, como a construção do Projeto Político Pedagógico da escola e de conselhos escolares, é parte obrigatória.

No tocante à segurança, o art. 144 define que a segurança pública é dever do Estado, direito e responsabilidade de todos e deve ser exercida para a preservação da ordem pública. Ao definir os órgãos responsáveis pela garantia desse direito, elenca as diferentes polícias, dentre elas as polícias militares e corpos de bombeiros militares. O $\int 5^{\circ}$ do citado artigo estabelece que "Às polícias militares cabem a polícia ostensiva e a preservação da ordem pública; aos corpos de bombeiros militares, além das atribuições definidas em lei, incumbe a execução de atividades de defesa civil". Analisando educação e segurança, embora não reste dúvidas tratar-se de dois direitos fundamentais na vida em sociedade, também não há dúvidas que são duas áreas com especificidades distintas, que contam com lógicas frontalmente opostas na sua operacionalização e que possuem princípios completamente divergentes.

Colocado isso, retomamos o pressuposto de que a garantia do direito à educação deve considerar o movimento de superação das estruturas de poder e o intenso processo de lutas de classes para levantar algumas questões. A quem interessa destituir a escola pública, laica, gratuita e de qualidade, socialmente referenciada, de suas funções sociais? É possível pensar a Polícia Militar como um insumo necessário e profícuo para garantia do direito à educação de qualidade dos cidadãos e das cidadãs brasileiras que estudam nas escolas públicas? A 
educação pensada em uma escola que funciona no regime do quartel é capaz de garantir o pleno desenvolvimento dos diferentes sujeitos e suas especificidades? A formação para obediência serve a superação das desigualdades resultantes pelas diferenças de classe ou para manutenção da ordem estabelecidas e a naturalização das desigualdades de classe, raça, etnia, gênero e orientação sexual? É capaz de respeitar as diferentes manifestações culturais, religiosas e identitárias e garantir o desenvolvimento dos sujeitos e suas diversidades?

A partir dos argumentos aqui levantados, concluímos que a militarização das escolas conserva, defende e cultiva divisões, discriminações, abismos de desigualdade e apagamento das individualidades. Dessa forma, evidenciouse o caminho de negação do direito à educação e da efetivação do princípio da qualidade socialmente referenciada.

\section{CONSIDERAÇÕES FINAIS}

A escola tem sido quase sempre o último dos refúgios para o preconceito, a rotina, o dogma, o tradicionalismo cego ou os interesses mais egoísticos. Pobre escola! É a mais humilde, a mais mandada das instituições e, ao mesmo tempo, o bode expiatório de todas as nossas deficiências. Dela tudo se espera e nada lhe permite! Quanto mais abandonada mais culpada fica de tudo o que nos suceda (TEIXEIRA, 1959, p. 8).

Ao analisar a efetivação da garantia do direito à educação com qualidade, na proposta do modelo de militarização de escolas públicas, este artigo evidenciou um contexto de fortalecimento do conservadorismo e de ofensiva à escola e à educação públicas. Na pauta das políticas em implementação, os discursos de governantes reforçam a concepção de educação conservadora, impositiva e preconceituosa que está em voga, como transparecem as falas seguintes:

1. Governador Ibaneis (DF): "esse é um projeto de governo. Quem quiser barrar que vá à justiça [...]. Não vou deixar a cidade ser aprisionada por uma esquerda que ficou no passado, tendo a oportunidade de governar e não fez nada para a sociedade (FORTUNA, 2019).

2. Ministro da Educação Abranham Weintraub (dia 5 de setembro de 2019, na cerimônia de lançamento do Programa Nacional de Escolas Cívico Militares): "nunca mais um regime totalitário tente ser implantado no Brasil [...]. Nunca mais a gente se esqueça que nossa bandeira jamais será vermelha" (SALDAÑA; COLETTA, 2019).

3. Presidente da República Jair Messias Bolsonaro (dia 5 de setembro de 2019, na cerimônia de lançamento do Programa Nacional de Escolas Cívico Militares) "Temos aqui a presença física do nosso governador do DF, Ibaneis. 
Parabéns, governador, com essa proposta. Vi que alguns bairros tiveram votação e não aceitaram. Me desculpa, não tem que aceitar, não. Tem que impor... me desculpa, não tem que perguntar para o pai, irresponsável nesta questão, se ele quer ou não uma escola, de certa forma, com militarização. Tem que impor, tem que mudar" (MAUZI, 2019).

Tais falas demonstram, ainda, que a suposta luta contra as ideologias de esquerda praticadas na escola e a dita neutralidade do Estado fundem-se ao ideário do militarismo, promovendo uma fratura no sentido de escola pública para todos.

Retomando Anísio Teixeira (1959), mais uma vez, a escola pública é colocada como a principal causa das mazelas da educação brasileira, indiscriminadamente excluindo-se os diversos fatores que estão para além dos muros da escola e que interferem na sua qualidade. A ela se impõe um modelo antidemocrático, controlador e que revela, em sua essência, as marcas da perpetuação das desigualdades e do não acesso à educação como direito social e de todos.

Por fim, é mister registrar os limites das análises aqui apresentadas, cabendo a motivação e o incentivo a estudos que possam avaliar os resultados do modelo de escolas militarizadas e do seu processo de implementação.

\section{REFERÊNCIAS}

BRASIL. MINISTÉRIO DA EDUCAÇÃO. Compromisso Nacional pela Educação Básica. Brasília: Ministério da Educação, 2019. Disponível em: http:/ / portal.mec.gov.br/images/11.07.2019_PPT-Cafe-da-manha-EB-converted.pdf. Acesso em: 2 set. 2019.

BRASIL. [Constituição (1988)]. Constituição da República Federativa do Brasil de 1988. Brasília, DF: Presidência da República, [2016]. Disponível em: http://www.planalto.gov.br/ccivil_03/constituicao/constituicao.htm. Acesso em: 1 set. 2019.

BRASIL. [LDB (1996)]. Lei de Diretrizes e Bases da Educação Nacional de 1996. Brasília, DF: Presidência da República, [2016]. Disponível em: http://www. planalto.gov.br/ccivil_03/LEIS/L9394.htm. Acesso em: 01 set. 2019. 
BRASIL. Lei $\mathbf{n}^{\mathbf{0}} \mathbf{9 . 7 8 6}$, de 8 de fevereiro de 1999. Dispõe sobre o ensino no exército brasileiro e dá outras providências. Brasília, DF: Casa Civil, [1999]. Disponível em: http://www.planalto.gov.br/ccivil_03/leis/L9786.htm Acesso em: 04 set. 2019.

BRASIL. Decreto $\mathbf{n}^{\circ}$ 3.182, de 23 de setembro de 1999. Regulamenta a Lei $n^{\circ}$. 9.786, de 08 de fevereiro de 1999, que dispõe sobre o ensino no exército brasileiro e dá outras providências. Brasília, DF: Casa Civil, [1999]. Disponível em: http:/ / www.planalto.gov.br/ccivil_03/decreto/D3182.htm. Acesso em: 05 set. 2019.

BRASIL. Decreto $\mathbf{n}^{\circ} \mathbf{9 . 1 7 1}$, de 17 de outubro de 2017. Altera o Decreto n $^{\circ} 3.182$, de 23 de setembro de 1999, que regulamenta a Lei no 9.786, de 8 de fevereiro de 1999, que dispõe sobre o ensino no Exército Brasileiro. Brasília, DF: Casa Civil, [2017]. Disponível em: http://www.planalto.gov.br/ccivil_03/_ato20152018/2017/decreto/D9171.htm. Acesso em 03 set. 2019.

BRASIL. Lei $\mathbf{n}^{\circ} \mathbf{7 . 2 8 9}$, de 18 de dezembro de 1984. Dispõe sobre o Estatuto dos Policiais-Militares da Polícia Militar do Distrito Federal e dá outras providências. Brasília, DF: Casa Civil, [1984]. Disponível em: http://www.planalto.gov.br/ ccivil_03/leis/17289.htm. Acesso em: 30 ago. 2019.

BARBOSA, Rui. Obras seletas, v. 7. Rio de Janeiro, 1893. Biblioteca Digital de Literaturas de Língua Portuguesa. Disponível em: https://www.literaturabrasileira. ufsc.br $/$ documentos $/$ ?action= download\&id $=43456 \#$ PELOEX $\%$ C3\%89RCIT OCONTRA. Acesso em: 4 set. 2019.

BELLONI, Isaura. Educação. In: BITTAR, Jorge (org.). Governos estaduais: desafios e avanços: reflexões e relatos de experiências petistas. São Paulo: Perseu Abramo, 2003.

BOLSONARO sobre altos custos de colégios militares: "investimento maior na educação deve ser a regra. O Antagonista, São Paulo, 27 ago. 2018. Disponível em: https://www.oantagonista.com/brasil/bolsonaro-sobre-alto-custo-decolegios-militares-investimento-maior-na-educacao-basica-deve-ser-regra/. Acesso em: 6 set. 2019. 
CARVALHO, Cristina Helena Almeida de. Financiamento da educação básica: estrutura atual e desafios futuros. In: ROCHA, Maria Zélia Borba; PIMENTEL, Nara Maria (Org.). Organização da Educação Brasileira: marcos contemporâneos. Brasília: Editora da Universidade de Brasília, 2016.

ANDE; ANPED; CEDES. Carta de Goiânia. Educação \& Sociedade, ano VIII, número 25, dezembro de 1986, pp. 5-10.

CHAUÍ, Marilena. Direitos Humanos e Medo. [entre 2000-2010]. Disponível em: http://www.dhnet.org.br/direitos/textos/humanismo/chaui.html. Acesso em: 3 set. 2019.

CHAUÍ, Marilena. Direitos humanos e medo. In: RIBEIRO FESTER, A C. Direitos humanos. São Paulo: Brasiliense, 1989.

CUNHA, Luiz Antônio. O projeto reacionário de educação. 2016. Disponível em: http://www.luizantoniocunha.pro.br/uploads/independente/ProjReacEd_ livro.pdf. Acesso em: 4 set. 2019.

DOURADO, Luiz Fernandes; OLIVEIRA, João Ferreira de. A qualidade da educação: perspectivas e desafios. Cad. CEDES, Campinas, v. 29, n. 78, p. 201 215, ago. 2009. Disponível em: http://www.scielo.br/scielo.php?script=sci_ arttext\&pid=S0101-32622009000200004\&lng=en\&nrm=iso. Acesso em: 1 set. 2019.

FLACH, Simone de Fátima. Qualidade social da educação: uma concepção na perspectiva democrática. In: NASCIMENTO, Maria Isabel M.; LOMBARDI, José Claudinei; SAVIANI, Dermeval (org.). Caderno de resumos da VI Jornada do HISTEDBR (Nacional). Campinas: Graf. FE: HISTEDBR, 2005.

FORTUNA, Deborah. 'Quem quiser barrar, que vá à Justiça”, diz Ibaneis sobre PM em escolas. Correio Braziliense, Brasília, 19 ago. 2019. Disponível em: https://www.correiobraziliense.com.br/app/noticia/cidades/2019/08/19/ interna_cidadesdf,778051/quem-quiser-barrar-que-va-a-justica-diz-ibaneissobre-pm-em-escolas.shtml. Acesso: 3 set. 2019.

GÓES, Moacyr de; CUNHA, Luiz Antônio. O golpe na educação. Rio de Janeiro: Zahar, 1988. 
LENHARDT, Gero; OFFE, Claus. Teoria do Estado e Política Social. In: OFFE, Clauss. Problemas estruturais do Estado capitalista. Rio de Janeiro: Tempo Brasileiro, 1984.

MARX, Karl; ENGELS, Friedrich. Manifesto do Partido Comunista. Petrópolis: Vozes, 1999.

MARX, Karl. Contribuição à crítica da economia política: Textos sobre educação e ensino. Rio de Janeiro: Moraes, 1992.

MINISTÉRIO PÚBLICO DO DISTRITO FEDERAL E TERRITÓRIOS. Nota técnica $\mathbf{n}^{\mathbf{0}}$ 001/2019 - Proeduc/MPDFT. Projeto Escola de Gestão Compartilhada. Brasília: MPDFT, 2019. Disponível em: http://www.mpdft. $\mathrm{mp} . \mathrm{br} /$ portal/pdf/unidades/promotorias/proeduc/notas_tecnicas/Nota_ tecnica_Proeduc_2019_001_escola_gestao_compartilhada_SEEDF_SSPDF.pdf. Acesso em: 02 set. 2019.

ORGANIZAÇÃO NACIONAL DAS NAÇÕES UNIDAS. Declaração Universal dos Direitos Humanos. Rio de Janeiro: UNIC, 2009. Disponível em: https://nacoesunidas.org/wp-content/uploads/2018/10/DUDH.pdf. Acesso em 30 ago. 2019.

MAZUI, Guilherme. Bolsonaro defende 'impor' escolas cívico-militares para cidadão não depender de programas sociais. G1, Brasília, 5 set. 2019. Disponível em: https://g1.globo.com/politica/noticia/2019/09/05/bolsonaro-defendeimpor-escolas-civico-militares-para-cidadao-nao-depender-de-programas-sociais. ghtml. Acesso: 7 set. 2019.

PENIN, Sonia T. Sousa; VIEIRA, Sofia Lerche. Refletindo sobre a função social da escola. In: VIEIRA, Sofia Lerche (Org.) Gestão da escola: desafios a enfrentar. Rio de Janeiro: DP\&A Editora (Biblioteca ANPAE), 2002, p. 13-45.

PONCE, Aníbal. Educação e luta de classes. São Paulo: Cortez, 2001.

SALDAÑA, Paulo; COLETTA; Ricardo Della. Governo prevê 216 escolas militares até 2023 e Bolsonaro diz que modelo tem de ser imposto. Folha de São Paulo, São Paulo, 5 set. 2019. Disponível em: https://www1.folha.uol.com.br/ educacao/2019/09/governo-preve-216-escolas-militares-ate-2023-e-bolsonarodiz-que-modelo-tem-de-ser-imposto.shtml. Acesso em 5 set. 2019. 
TEIXEIRA, Anísio. Só a escola pública fundará a República. Diário de Notícias, Rio de Janeiro, p. 4. edição 11351, 1959. Disponível em: http://memoria.bn.br/ DocReader $/$ DocReader.aspx?bib $=093718 \_03 \&$ PagFis $=87543 \&$ Pesq $=0 \% 20$ ensino $\% 20$ cabe $\% 20 \%$ c3\%a0\%20sociedade. Acesso em: 4 set. 2019.

TRIBUNAL DE JUSTIÇA DE RONDÔNIA. Ação direta de inconstitucionalidade (ADI). Rondônia: TJ/RO. Disponível em: https://tjro.jusbrasil.com.br/jurisprudencia/723810609/direta-de-inconstitucionalidadeadi-8026406120178220000-ro-0802640-6120178220000/inteiro-teor723810610 ?ref=juris-tabs. Acesso em: 5 set. 2019.

ANDRÉIA MELLO LACÉ, Professora Adjunta da Faculdade de Educação da Universidade de Brasília. Doutora em Educação pela Universidade de Brasília na linha de pesquisa: Políticas Públicas e Gestão da Educação.

E-mail: andreia.mello.lace@gmail.com

ORCID: https://orcid.org/0000-0002-3549-2696

CATARINA DE ALMEIDA SANTOS, Professora Adjunta da Faculdade de Educação da Universidade de Brasília, Doutora em Educação pela USP.

E-mail: cdealmeidasantos@gmail.com

ORCID: https://orcid.org/0000-0003-1864-4608

DANIELLE XABREGAS PAMPLONA NOGUEIRA, Professora Adjunta da Faculdade de Educação da Universidade de Brasília, Doutora em Educação pela UnB, atuando na área de Políticas Públicas, Gestão e Tecnologias Educacionais E-mail: danielle.pamplona@gmail.com

ORCID: https://orcid.org/0000-0001-8500-0402

Recebido em setembro de 2019 Aprovado em outubro de 2019 